\title{
ANTIESTREPTOLISINAS EN LAS PACIENTES EMBARAZADAS HIPERTENSAS
}

Doctor Enrique Leaño Flórez

\section{INTRODUCCION}

Hipertensión, proteinuria y edemas no son patrimonio de la toxemia de la mujer gestante. Pensar con tal criterio es concebir un concepto demasiado simplista, a la vez pretender que a la mujer embarazada le son ajenas otras noxas que pueden resultar de mayor gravedad si no son apreciadas y evaluadas de manera oportuna y correcta.

El diagnóstico diferencial de la toxemia gravídica debe plantearse con aquellas entidades que, acompañándose de hipertensión, proteinuria y edemas, hacen su aparición y comprometen la evolución fisiológica de una mujer embarazada. Detalle muy importante lo constituye el hecho de que no es preciso que todos los signos y síntomas estén presentes para poder hacer un diagnóstico correcto. Muy por el contrario, la precocidad y sagacidad con que se juzgue la aparición cronológica de ellos ponen de presente el buen criterio del clínico.

De una manera más o menos estereotipada y empírica, con enorme fre- cuencia se catalogan cuadros clínicos ajenos a la toxemia como dependientes de ella porque hacen su aparición durante el embarazo. Los errores de diagnóstico lógicamente conllevan una terapéutica equivocada con las siguientes repercusiones, incidentes y no pocos fracasos aun de carácter mortal para la madre o el producto de concepción.

Obviamente se concluye de lo anterior que resulta cada vez más importante aportar el mayor número de datos clínicos y el más grande acervo de conocimientos paraclínicos que contribuyan a dilucidar el problema diagnóstico.

Es tan complicado el problema diagnóstico que, aun reuniendo el mayor número de datos clínicos y las pruebas de laboratorio, puede resultar imposible la confirmación de la sospecha diagnóstica, lo cual impone el control post-parto durante un tiempo bastente largo, como lo insinúa Dieckman. 
Afortunadamente cada día se conocen nuevas técnicas y procedimientos que tienden a facilitar el diagnóstico. El aporte que en tal sentido se haga y divulgue puede resultar de gran importancia.

Pretendemos en el presente trabajo exponer las bases fundamentales por medio de las cuales se puede, en la actualidad, enfocar el problema de diagnóstico diferencial de las toxemias del embarazo con un grupo de entidades nosológicamente muy disímiles pero con apariencias clínicas comunes. Trataremos de ser breves en los aspectos más conocidos, para detenernos en algunos aspectos que pueden tener alguna novedad, y principalmente mostrar nuestra experiencia en la investigación de la existencia de procesos inflamatorios en la paciente embarazada, y que por su ubicación pueda dar lugar a disturbios orgánicos y particularmente renales que, dando sintomatología similar a la de la toxemia, se prestan a confusiones de diagnosis.

¿Cuáles son las entidades con las cuales se puede confundir la toxemia gravídica?

Fundamentalmente hemos de mencionar: la hipertensión arterial, de origen indeterminado o esencial, las nefropatías, principalmente hipertensivas, y las afecciones de carácter endocrino, principalmente de naturaleza tiroidiana y pancreática, y algunas entidades hipertensinógenas cuyo modelo puede ser el feocromocitoma.
Los elementos de que nos valemos para diferenciar estas entidades son los siguientes: $1^{\circ}$. Historia clínica. $2^{\circ}$. La evolución. $3^{\circ}$. El examen clínico. $4^{\circ}$. La respuesta terapéutica. $5^{\circ} \mathrm{El}$ laboratorio. $6^{\circ} \mathrm{El}$ estudio anatomopatológico.

Desde luego prescindimos en el presente estudio del capítulo que hace relación con el diagnóstico diferencial de la eclampsia, teniendo en cuenta que no es nuestra intención adentrarnos en el terreno de las entidades convulsivantes sino concretarnos a la toxemia gravídica en general.

\section{Iํ. Historia clínica}

La anamnesis cuidadosa de la embarazada nos permite obtener datos muy valiosos para el diagnóstico.

Edad: Si estamos ante pacientes que se encuentran en los límites de la edad procreacional, bien sea en las muy jóvenes o en las "añosas" debemos pensar con más insistencia en la posibilidad de que estemos tratando a una mujer gestósica. Es en esta época de la vida cuando la embarazadia hace con mayor frecuencia toxemia. El factor anterior tiene relación íntima con la paridad, pues bien sabemos cómo la pre-eclampsia ataca con mayor frecuencia a las primigestantes. No debe olvidarse que tratándose de afecciones de carácter inflamatorio de naturaleza infecciosa, tal como ocurre con las pielonefritis y las glomerulonefritis, el dato de la 
edad de la paciente no constituye elemento valioso para el juicio diagnóstico, puesto que estará igualmente tan expuesta la paciente joven como la "añosa". Con mayor frecuencia la hipertensión arterial esencial hace su aparición más tardíamente en relación con la edad de las pacientes, sin que este dato tenga validez absoluta. Si tenemos en consideración el caso de la paciente afectada por la dibetes hemos de recordar que la concepción rara vez es posible, y la evolución de un embarazo se ve interrumpida precozmente, a menos que una terapéutica activa y precoz permita su continuidad. Los exámenes de laboratorio, fácilmente permiten la diferenciación mediante un simple estudio de la glicemia. Los estados prediabéticos rara vez dan una sintomatología tan ruidosa como para dar lugar a confusión diagnóstica.

Hipertiroidismo, feocromocitoma y el factor edad no tienen ninguna relación para efectos de diagnóstico. Igualmente pierde interés la correlación entre estas entidades y la paridad de la paciente.

\section{2․ Evolución}

Excepcionalmente la toxemia gravídica hace su aparición antes de la 26 semana. En presencia de una paciente embarazada que manifiesta sintomatología compatible con toxemia, deben descartarse todas aquellas entidades con las cuales podría prestarse a confusión antes de hacer este diagnóstico. Desde luego se escapan a esta eventualidad las casos de mola hidatiforme, polihidramnios y embarazo múltiple, circunstancias estas en las cuales es posible la instalación del estado toxémico. En primigestantes muy jóvenes se han observado, los más graves estados de toxemia, inclusive en la fase eclámptica, durante los primeros meses, pero su ocurrencia es excepcional.

Antecedentes familiares: De todos es sabida la importancia que adquiere el factor herencia en la presencia de hipertensión esencial a través de la descendencia. Hasta tal punto es importante este dato que en la investigación de toda paciente hipertensa en estudio, la ausencia de este factor resta validez a toda sugerencia diagnóstica. La hipertensión arterial esencial tiene un substrato familiar determinante, y muchos casos que se catalogan dentro de las toxemias no son otra cosa que formas clínicas de hipertensión arterial. Desafortunadamente, en muchas ocasiones, y más cuando se trata de pacientes de condición hospitalaria, este dato tan valioso no se puede obtener. Insistir en su investigación es muy recomendable. Hay quienes piensan que el embarazo hace aparentes cuadros de hipertensión esencial que permanecían latentes. El embarazo se constituiría así en un factor desencadenante. La investigación postnatal parece confirmar esta sospecha.

Antecedentes infecciosos: piodermitis, anginas, etc.

Evolución: La aparición de signos y síntomas en los primeros meses de 
embarazo debe orientarnos hacia entidades no propiamente de naturaleza obstétrica: hipertensión, edemas y proteinuria, en concomitancia o independientemente, deben orientar la investigación hacia la existencia de nefropatías, endocrinopatías, afecciones del tejido cromafín o hipertensión esencial. Sí, por el contrario, este grupo de síntomas aparece en el último trimestre es muy posible que estemos en presencia de pre-eclampsia, y la hipótesis será tanto más valedera cuanto más cerca del término se encuentre la gestación.

\section{$3^{\circ}$. Examen clínico}

Desde luego los datos obtenidos mediante el examen cuidadoso constituyen el elemento fundamental para el diagnóstico. Hacemos énfasis en el aumento exagerado de peso, en la existencia y forma de distribución del edema, en el tipo de hipertención arterial; constante, oscilante, en crisis, así como también su progresión. Con frecuencia la localización y forma de aparición de los edemas orientan hacia determinado tipo de afección: edemas descendentes con iniciación facial y matinal inclinan el diagnóstico al padecimiento renal. Hipertensión con alternativas que se acompañan de trastornos vasomotores de naturaleza neurovegetativa hacen sospechar la presencia de endocrinopatías del tipo de la tirotoxicosis o de hiperfunción cromafín, como ocurre en pacientes portadoras de un feocromocitoma. Hipertensión constante y sin mayores variaciones ni fenómenos secundarios hacen pen- sar en paciente con hipertensión esencial. Capítulo muy importante constituye la fundoscopia ocular. El estudio del aspecto de fondo de ojo es tan importante en el diagnóstico diferencial de la toxemia gravídica que su práctica debe ser rutinaria. Este examen permite afirmar o descartar la existencia de un padecimiento extraño a la toxemia y nos da idea de la magnitud del compromiso vascular. En términos generales, una imagen de fondo de ojo del tipo I y II de la clasificación de Keicht Wagener nos indica que el daño vascular puede ser exclusivamente funcional, como ocurre en la toxemia gravídica. Imágenes del tipo III y IV hablan en favor de procesos a los cuales excepcionalmente conduciría una toxemia gravídica, y serían más bien patrimonio de aquellos procesos que, como la hipertensión crónica y severa esencial o secundaria, conducirían a la formación de exudados, hemorragias y edema papilar. En esta eventualidad estarían incluídas entidades tales como la glomerulonefritis, pielonefritis, la tirotoxicosis, el feocromocitoma y en general la hipertensión maligna de cualquier naturaleza. De lo anterior se concluye que si un fondo de ojo normal no tiene mayor importancia, desde el punto de vista del diagnóstico diferencial, un fondo de ojo positivo permite confirmar de manera definitiva la existencia de un proceso extraño a la toxemia.

Es igualmente importante, dentro del examen clínico, el análisis de las 
condiciones obstétricas. Bien sabemos que los estados de sobredistensión uterina se acompañan de toxemia gravídica. El embarazo múltiple, el polihidramnios y el feto gigante frecuentemente dan lugar a estados de toxemia por aumento de la presión intraabdominal y excitación de los ganglios del sistema simpático, con la consiguiente excreción patológica de substancias presoras del tipo de la epinefrina y norepinefrina.

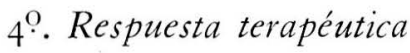

Tal como se ha establecido en investigaciones realizadas en el IMI, el cuadro clínico de la toxemia cede rápidamente con la terapéutica allí sistematizada: fenobarbital, clorotiazida, acepromazina, dieta hiposódica. No ocurre lo mismo en los casos de pacientes que sufren de entidades de origen extraobstétricas, en quienes al iniciar la terapia hay una fase de mejoría que no sobrepasa de algunos días cuando la sintomatología remite.

\section{$5^{\circ}$. Laboratorio}

Examen parcial de orina, Rh y grupo sanguíneo, uricemia, proteinemia, cuadro hemático y serología son exámenes de rutina, junto con la azohemia, a practicar en toda paciente embarazada. Si nos enfrentamos a pacientes con sospecha de toxemia gravídica, la investigación debe abarcar un estudio nefrológico completo que debe incluír: urocultivo, recuento de colonias, investigación de células "glitter", frotis del sedimento. Su positividad afirmará el diagnóstico de pielonefritis. Igualmente importante será la titulación de antiestreptolisinas para descartar o afirmar la existencia de un proceso renal del tipo de la glomerulonefritis, el recuento de Addis, y, a ser posible, la práctica del examen del moco nasal. Si nos inclinamos hacia la posibilidad de un estado de tirotoxicosis, el metabolismo basal, la colesterolemia y la yodoproteinemia serán un auxilio valioso. La prueba de la regitina y la dosificación de catecolaminas nos confirmarán la sospecha de un feocromocitoma. La glicosuria y la glicemia altas nos indicarán la existencia de un estado diabético. El estudio electrocardiográfico y la radiología de la silueta cardíaca y grandes vasos nos prestarán ayuda en la confirmación de un estado de hipertensión esencial de larga evolución.

\section{El estudio anatomopatológico}

La biopsia percutánea del riñón se ha constituído en los últimos tiempos en un procedimiento valiosísimo en la investigación de los procesos a que hemos hecho mención. Gracias a ella ha sido posible la comprobación in vivo de las alteraciones propias de la toxemia, las nefropatías inflamatorias, las enfermedades del colágeno, el síndrome de Kimmestiel Wilson, la hipertensión arterial, etc. El estudio mediante el electromicroscopio abre nuevos campos a la investigación.

Como una contribución al esquema de estudio planteado anteriormente, hemos querido aportar nuestra experiencia en la investigación 
indiscriminada de posibles procesos renales del carácter de la glomerulonefritis en pacientes a quienes se les sospechó inicialmente un estado toxémico. Con tal fin presentamos los resultadios obtenidos por medio de la cuantificación de antiestreptolisinas en el torrente circulatorio de las enfermas previamente catalogadas como toxémicas en el servicio correspondiente del ICSS.

\section{ANTIESTREPTOLISINAS}

Así se denominan a los anticuerpos desarrollados en el organismo que han sufrido en un pasado inmediato una infección por estreptococo del grupo A.

Los estreptococos (I) pertenecen a la familia cocácea. Son gérmenes Gram $\left(^{+}\right)$redondos, y que se pueden encontrar solos, en grupos o en cadenetas cortas o largas. Estas últimas son características de las cepas patógenas. En medio líquido se aprecian como "miga de pan". En agar nutritivo forman colonias opacas, redond'as y de bordes enteros.

Según su hemólisis se pueden clasificar en agar sangre en: estreptococos alfa, beta y gama. Los estreptococos alfa presentan un ligero halo alrededor de la colonia como el grupo viridans. Los beta presentan una hemólisis total alrededor de la colonia, como en el caso del estreptococo beta hemolítico. Los gama no presentan ninguna hemólisis ni halo.

El título de antiestreptolisinas (TAES) (2) se utiliza como coad- yuvante en el diagnóstico de enfermedades tales como la fiebre reumática, el eritema nudoso y la glomerulonefritis. Su aumento significativo constituye un signo de infección por estreptococo del grupo A.

Procedimiento para la determinación del título de antiestreptolisinas:

Se obtiene sangre venosa, no hemolizada, que se deja coagular. Se separa el coágulo y se centrifuga hasta cuando el suero esté libre de células. El suero así obtenido se incuba durante $30^{\prime}$ a $5^{6^{\circ}} \mathrm{C}$. Las diluciones del suero se efectúan de la siguiente manera:

A. $0.5 \mathrm{ml}$ de suero.

$4.5 \mathrm{ml}$ de solución reguladora (dilución $\mathrm{r}: \mathrm{IO})$.

B. r.o $\mathrm{ml}$ de la dilución de suero I:IO.

$9.0 \mathrm{ml}$ de solución reguladora (dilución $\mathrm{I}: \mathrm{IO0})$.

C. $2.0 \mathrm{ml}$ de la dilución $\mathrm{r}: \mathbf{1 0 0} \mathrm{del}$ suero.

8.0 $\mathrm{ml}$ de la solución reguladora (dilución r:500).

Se prepara una serie de tubitos de ensayo de I x $7.5 \mathrm{~cm}$ y se los marca con el número de la muestra y el número de serie del tubito (por ejemplo: 2.150-I, 2.150-2, 2.150-3, etc).

Se agregan el suero diluído y la solución reguladora, según se indica en la tabla I.

Se agregan $0.5 \mathrm{ml}$ de estreptolisina "O" rehidratada a cada tubo y 
también al tubo de control hemolítico, y luego se incuba el conjunto durante $15^{\prime}$ a $37^{\circ} \mathrm{C}$. en baño de agua.

Se agregan $0.5 \mathrm{ml}$ de una suspensión reguladora al $5 \%$ de eritrocitos del grupo o recientemente desfibrinada y lavada. Se agita bien y se incuba durante 15 ' en un baño de agua a $37^{\circ} \mathrm{C}$. Se agita nuevamente y se vuelve a incubar durante $30^{\circ}$ en el baño a $37.5^{\circ} \mathrm{C}$. Se sacan los tubos, se agitan bien y se centrifugan luego durante 3' a $\mathbf{1} .800$ revoluciones por minuto.

Se comprueba la existencia o no de hemólisis en el líquido sobrenadante. Se toma como punto extremo el tubo de mayor dilución que no exhiba hemólisis ante una luz blanca y fuerte.

\section{Interpretación}

Para Rantz, Di Capio y Randall, un título de antiestreptolisinas de 50 U. o menos es un firme signo en contra de fiebre reumática o glomerulonefritis. La infección estreptocócica, aun hasta un breve tiempo después de su curación da aumentos hasta 500 U. o más. De gran ayuda diagnóstica para establecer la presencia o no de fiebre reumática o de glomerulonefritis es más importante la observación de un título bajo que la de uno alto. Por otra parte, las variaciones en los títulos de muestras seriadas son más importantes e informadoras que el examen de muestras aisladas.
McCarty y otros investigadores han conceptuado que la mayoría de los enfermos con fiebre reumática tienen un título promedio de $500 \mathrm{U}$. por $\mathrm{ml}$, y que por otra parte puede considerarse como dentro de los límites normales un título de $150 \mathrm{U}$.

En relación con la glomerulonefritis, la titulación de antiestreptolisinas (anticuerpos contra la hemolisina estreptococica) se eleva a altos niveles, como corresponde a un estado de hipersensibiildad en el proceso de inmunización (Fishberg). Las investigaciones de Kay concuerdan con la hipótesis de que la glomerulonefritis resulta de la interacción de anticuerpos (antiestreptolisinas) con un antígeno formado por la acción de algún producto de la infección estreptocócica sobre el riñón.

De lo anterior se concluye que, siendo la glomerulonefritis una entidad con la cual se puede confundir la toxemia gravídica, resulta muy importante la titulación de antiestreptolisinas como un método auxiliar de gran valor en el diagnóstico diferencial de las dos entidades. Un título alto de antiestreptolisinas nos debe inclinar hacia la existencia de un proceso inmunológico de carácter bacteriano. El punto de partida frecuentemente se encuentra localizado en la piel, en los senos paranasales, las amígdalas, oídos, etc. Resulta así particularmente importante la exploración clínica minuciosa en vía de localizar el foco séptico, a partir del cual se desencadena el trastorno renal. 


\section{MATERIAL Y METODOS}

El material humano utilizado en el presente trabajo se obtuvo en el Servicio de Toxemias de la Clínica I $^{\text {Q }}$ de Mayo, de los Seguros Sociales, de Bogotá.

Se trató de investigar la frecuencia de infección estreptocócica de las pacientes allí hospitalizadas con el diagnóstico de toxemia gravídica. En la anamnesis se hizo hincapié en los antecedentes infecciosos, renales, e hipertensivos, y en el examen clínico la búsqueda de focos sépticos particularmente en amígdalas, senos paranasales, dentadura. Igualmente se tuvo en cuenta la evolución del proceso, desde el punto de vista renal, y si éste se acompañó de fiebre, edemas o hipertensión. La presencia de cambios en el aspecto de fondo de ojo también fue determinada.

\section{RESUMEN}

Como se puede observar en los esquemas anteriores, la investigación abarcó un mayor número de pacientes multigestantes. Casi todas las enfermas acusaban antecedentes infecciosos $(90 \%)$, y solamente el $10 \%$ no los refirieron. Fue muy frecuente el hallazgo de infección y focos sépticos a nivel de la dentadura y las amígdalas. También las otitis supuradias, el acné, la forunculosis, los estados gripales, las piodermitis con formación de abscesos, las mastitis, bronquitis y apendicitis fueron registrados.
El $2 \mathbf{I} .43 \%$ de las pacientes tenía antecedentes de afección renal, y el $25.71 \%$, de estados hipertensivos previos.

Dentro de la evolución de la enfermedad por la cual consultaron, la hipertensión, los edemas, la epigastralgia, la cefalea, el vómito, la polaquiuria con disuria y la fiebre fueron los signos y síntomas más importantes. La evolución del proceso se extendió desde 3 días hasta 3 meses. Fueron eclámpticas 4 pacientes. El mayor número, 54, de las pacientes revelaron alteraciones del fondo de ojo, caracterizadas principalmente por angioespasmo en grado diverso de intensidad.

El edema fue localizado a la región maleolar en la mayoría de las enfermas. Una paciente llegó a la anasarca.

El examen de orina practicado a todas las pacientes reveló datos contradictorios, en relación con la gravedad de los hallazgos clínicos, pero sí fue absoluta la presencia de cilindruria en las enfermas eclámpticas.

En relación con el título de antiestreptolisinas, objetivo principal de nuestro estudio, encontramos que entre 70 pacientes investigadas, un número grande de enfermas, I6, dieron cifras por encima de 150 unidades Todd. A ellas haremos referencia especial.

El primer caso se trató de una paciente con antecedente de angina y presencia de abscesos dentarios, sin 
antecedentes renales o hipertensivos. El proceso se inició con fiebre, edema e hipertensión. El edema fue palpebral y maleolar. No hubo manifestaciones de hipertensión en fondo de ojo. El examen de orina demostró discretas piuria, leucocituria y bacteriuria. El TAES arrojó cifra de $333 \mathrm{U}$.

Cuatro pacientes tuvieron un TAES de 250 U., y tres de ellas padecieron de forunculosis y acné. Solamente una no refirió antecedentes infecciosos recientes. Ninguna había tenido padecimientos renales. Al uroanálisis, ninguna demostró proteinuria dosificable.

Once enfermas dieron un TAES de iı6 U. Todd, y todas ellas tenían antecedentes infecciosos. Algunas de ellas, 5, incluyeron la febrícula o la fiebre dentro de su sintomatología.

A manera de resumen debemos advertir que no fue nuestra intención fundamental realizar un estudio exhaustivo, desde el punto de vista nefrológico ni inmulógico. Tampoco pretendimos que al practicar la titulación de antiestreptolisinas estuviéramos aclarando de manera definitiva el problema de diagnóstico de las pacientes embarazadas o puérperas con hipertensión, proteinuria o edemas. Simplemente y pensando que muchas de dichas enfermas pudieran tener una patología extraña al estado gestacional, nos propusimos demostrarla, como en efecto lo obtuvimos.

La titulación de antiestreptolisinas nos enseñó que un número aprecia- ble de pacientes, catalogadas a priori como toxémicas, padecían un proceso anterior o concomitante a su embarazo, y desencadenado o agravado por él pero ajeno al cuadro clínico de la pre-eclampsia-eclampsia.

El hecho de que i6 pacienes con sintomatología urinaria e hipertensiva y títulos altos de antiestreptolisinas, entre 70 enfermas investigadas indiscriminadamente estuviera presente, nos está demostrando la incidencia tan alta de actividad estreptocócica en nuestras pacientes obstétricas. Desde el punto de vista sanitario, este hecho es muy importante.

Necesariamente estos estudios, para un futuro, tendrán que complementarse con la investigación clínica completa, dentro de la cual no podrá prescindirse de los cultivos y frotis de orina, el recuento de colonias, la investigación de las células de Stenheimer Malvin, la electroforesis y el proteinograma, el recuento de Addis, la biopsia percutánea del riñón, etc., que nos conducirán entonces a un diagnóstico diferencial que nos permita visualizar más ampliamente los distintos aspectos de los padecimientos nefrológicos de las pacientes gestantes.

\section{CONCLUSIONES}

I $^{\text {a }}$ La titulación de antiestreptolisinas es un procedimiento de estudio que se puede efectuar en el medio hospitalario con relativa facilidad. 
$2^{\mathrm{a}}$ - De las 70 pacientes estudiadas, las multigestantes y multíparas con títulos altos de antiestreptolisinas fueron más frecuentes.

3. El número de pacientes con título alto de antiestreptolisinas fue significativamente grande.

4 a La investigación del título de antiestreptolisinas debe incluírse entre los procedimientos de diagnóstico en las pacientes presuntamente consideradas como toxémicas.

5. El título alto de antiestreptolisinas en una paciente embarazada está en favor de procesos renales ajenos a la toxemia gravídica pura.

6 a El título de antiestreptolisinas tiene no solamente valor diagnóstico. Es además una guía para la terapéutica.

$7^{\mathrm{a}}$ En el presente estudio, la investigación del TAES tuvo más valor estadístico que clínico.

\section{BIBLIOGRAFIA}

1. Stella Castellanos: Tesis de grado. Pág. 25. Capítulo II. Año de 1962.

2. LeVInSON, M. S., M. D., P. H. D. : Diagnóstico elínico de laboratorio. Pág. 876. Año de 1962. 